Kansas State University Libraries

New Prairie Press

\title{
CONFIDENCE INTERVALS FOR VARIANCE COMPONENTS IN ONE- WAY UNBALANCED DESIGNS
}

Franklin A. Graybill

Rana S. Fayyad

Follow this and additional works at: https://newprairiepress.org/agstatconference

Part of the Agriculture Commons, and the Applied Statistics Commons

\section{(c) (1) $\Theta(9$}

This work is licensed under a Creative Commons Attribution-Noncommercial-No Derivative Works 4.0 License.

\section{Recommended Citation}

Graybill, Franklin A. and Fayyad, Rana S. (1993). "CONFIDENCE INTERVALS FOR VARIANCE COMPONENTS IN ONE-WAY UNBALANCED DESIGNS," Conference on Applied Statistics in Agriculture. https://doi.org/10.4148/2475-7772.1368

This is brought to you for free and open access by the Conferences at New Prairie Press. It has been accepted for inclusion in Conference on Applied Statistics in Agriculture by an authorized administrator of New Prairie Press. For more information, please contact cads@k-state.edu. 


\title{
Confidence Intervals for Variance Components in One-way Unbalanced Designs
}

\author{
Franklin A. Graybill and Rana S. Fayyad \\ Colorado State University
}

\begin{abstract}
Consider the one way unbalanced components of variance model given by

$$
Y_{i j}=\mu+A_{i}+E_{i j},
$$

$\left(i=1, \ldots, a, j=1, \ldots, b_{i}\right)$ where $\mu$ is an unknown constant parameter, $A_{i}$ and $E_{i j}$ are independent normal random variables with zero means and variances $\sigma_{A}^{2}$ and $\sigma_{E}^{2}$ respectively.

The problem is to obtain a confidence interval for $\sigma_{A}^{2}$ with confidence coefficient greater than or equal to a specified $1-\alpha$. Three new procedures for obtaining confidence intervals for $\sigma_{A}^{2}$ are examined. These new methods are derived using unweighted means. These three methods are compared with a "standard" procedure based on confidence coefficients and expected "widths".
\end{abstract}

\section{Introduction}

In a one-way random effects model it is often of interest to find confidence intervals for the variance component $\sigma_{A}^{2}$. As an example suppose we are interested in the nitrogen content of the foliage in a large orchard. The two major sources of variation are the variance of nitrogen content for the leaves on a given tree $\left(\sigma_{E}^{2}\right)$ and the variance among the nitrogen contents of the trees in the orchard $\left(\sigma_{A}^{2}\right)$. In order to measure the nitrogen content, a random sample of trees from the orchard is collected and a random sample of leaves is taken from each tree; $Y_{i j}$ is the observed nitrogen content for the jth leaf from the ith tree sampled, and the 
model is a one-way random effects model $Y_{i j}=\mu+A_{i}+E_{i j}$. By observing $Y_{i j}$ we want to find a confidence interval estimate for $\sigma_{A}^{2}$ with confidence coefficient $1-\alpha$.

No method of obtaining exact confidence intervals for $\sigma_{A}^{2}$ has been given, but five approximate methods will be discussed here. Three of them give confidence coefficients very close to $1-\alpha$. One of these methods is the Tukey-Williams procedure and was developed independently by Tukey (1951) and Williams (1962). Another was developed independently by Moriguti (1954) and Bulmer (1957). The third was developed by Howe (1974). These three methods have confidence coefficients close to $1-\alpha$ and it has been proved by Wang (1990) that the confidence coefficient for the Tukey-Williams procedure is $\geq 1-\alpha$. Two other methods labeled method 4 and method 5 which are derived using Bonferroni's method have confidence coefficients $\geq 1-2 \alpha$. These five methods use the among sums of squares $=\sum_{i} \sum_{j}\left(\bar{Y}_{i .}-\bar{Y}_{. .}\right)^{2}$ and the within sums of square $=\sum_{i} \sum_{j}\left(Y_{i j}-\bar{Y}_{i .}\right)^{2}$ which are scaled chi-squared and are independent.

For the unbalanced case however the among sums of squares are no longer scaled chi-squared and hence a problem arises. Burdick and Graybill (1984) gave an approximate method for obtaining confidence intervals for $\sigma_{A}^{2}$ for the unbalanced case but this method does not always have a confidence coefficient greater than the specified $1-\alpha$.

In this article three new methods $\mathrm{A}, \mathrm{B}$ and $\mathrm{C}$ are proposed for finding confidence intervals for $\sigma_{A}^{2}$ for the unbalanced one-way design. At least one method, method $\mathrm{A}$, has confidence coefficient $\geq 1-\alpha$.

\section{The Balanced One-Way Classification}

Consider the one-way random effects model

$$
Y_{i j}=\mu+A_{i}+E_{i j} \quad i=1, \ldots, a ; \quad j=1, \ldots, b
$$

where $\mu$ is a constant parameter, $A_{i}$ and $E_{i j}$ are independent normal random variables with zero means and variances $\sigma_{A}^{2}$ and $\sigma_{E}^{2}$ respectively. An ANOVA table is

\begin{tabular}{|l|l|l|l|}
\hline $\begin{array}{l}\text { Source of } \\
\text { Variation } \\
(\mathrm{SV})\end{array}$ & $\begin{array}{l}\text { Mean Squares } \\
(\mathrm{MS})\end{array}$ & $\begin{array}{l}\text { Degrees of } \\
\text { Freedom } \\
(\mathrm{DF})\end{array}$ & $\begin{array}{l}\text { Expected } \\
\text { Mean Square } \\
(\text { EMS })\end{array}$ \\
\hline Factor A & $S_{A}^{2}$ & $n_{1}$ & $b \sigma_{A}^{2}+\sigma_{E}^{2}$ \\
Error & $S_{E}^{2}$ & $n_{2}$ & $\sigma_{E}^{2}$ \\
\hline
\end{tabular}

where 


$$
\begin{aligned}
& S_{A}^{2}=\sum_{j=1}^{b} \sum_{i=1}^{a}\left(\bar{Y}_{i .}-\bar{Y}_{. .}\right)^{2} / n_{1}, \\
& S_{E}^{2}=\sum_{1=1}^{a} \sum_{j=1}^{b_{i}}\left(Y_{i j}-\bar{Y}_{i .}\right)^{2} / n_{2},
\end{aligned}
$$

where $n_{1}=a-1, n_{2}=a(b-1), \bar{Y}_{i .}=\sum_{j=1}^{b} Y_{i j} / b$ and $\bar{Y}_{. .}=\sum_{j=1}^{b} \sum_{i=1}^{a} Y_{i j} / a b$. The random variables $\bar{Y}_{. .}, S_{A}^{2}$ and $S_{E}^{2}$ are complete sufficient statistics for this model, and $n_{1} S_{A}^{2} / E\left(S_{A}^{2}\right)$ and $n_{2} S_{E}^{2} / E\left(S_{E}^{2}\right)$ are independent chi-squared random variables with $n_{1}$ and $n_{2}$ degrees of freedom respectively.

For the balanced model in (1), we will display the five different methods referred to above for obtaining confidence intervals for $\sigma_{A}^{2}$.

Method 1: Tukey Williams (TW) Procedure

A $1-\alpha$ lower and upper confidence limit for $\sigma_{A}^{2}$ given by the TW procedure are $L_{T W}$ and $U_{T W}$, where

$$
L_{T W}=\left[S_{A}^{2}-\left(F_{1-\alpha: n_{1}, n_{2}} S_{E}^{2}\right)\right] / b F_{1-\alpha: n_{1}, \infty}
$$

and

$$
U_{T W}=\left[S_{A}^{2}-\left(F_{\alpha: n_{1}, n_{2}} S_{E}^{2}\right)\right] / b F_{\alpha: n_{1}, \infty} .
$$

Wang (1990) showed that $P\left[L_{T W} \leq \sigma_{A}^{2} \leq U_{T W}\right] \geq 1-\alpha$

Method 2: Howe (H) Procedure

The lower and upper $1-\alpha$ confidence bound for $\sigma_{A}^{2}$ given by Howe is $L_{H}$ and $U_{H}$ respectively where

$$
\begin{array}{ll}
L_{H}=(1 / b)\left[S_{A}^{2}-S_{E}^{2}-\sqrt{\left.\left[\left(1-F_{1-\alpha: n_{1}, \infty}^{-1}\right)^{2}\left(S_{A}^{2}\right)^{2}\right]+B\left(S_{E}^{2}\right)^{2}\right]}\right. & \text { if } \quad F \geq F_{1-\alpha: n_{1}, n_{2}} \\
L_{H}=0 & \text { if } \quad F<F_{1-\alpha: n_{1}, n_{2}}
\end{array}
$$

$$
\begin{array}{ll}
U_{H}=(1 / b)\left[S_{A}^{2}-S_{E}^{2}+\sqrt{\left.\left[\left(1-F_{\alpha: n_{1}, \infty}^{-1}\right)^{2}\left(S_{A}^{2}\right)^{2}\right]+A\left(S_{E}^{2}\right)^{2}\right]}\right. & \text { if } F \geq F_{\alpha: n_{1}, n_{2}} \\
U_{H}=0 & \text { if } F<F_{\alpha: n_{1}, n_{2}}
\end{array}
$$


where $F=\left(S_{A}^{2} / S_{E}^{2}\right), B=\left(1-F_{1-\alpha: n_{1}, n_{2}}^{2}\right)-F_{1-\alpha: n_{1}, n_{2}}^{2}\left(1-F_{1-\alpha: n_{1}, \infty}^{-1}\right)^{2}$, and $A=$ $\left(1-F_{\alpha: n_{1}, n_{2}}^{2}\right)-F_{\alpha: n_{1}, n_{2}}^{2}\left(1-F_{\alpha: n_{1}, \infty}^{-1}\right)^{2}$.

For the Howe procedure it is not known if $P\left[L_{H} \leq \sigma_{A}^{2} \leq U_{H}\right]$ is $\geq 1-\alpha$.

Method 3: Bulmer-Moriguti (BM) Procedure

The lower and upper $1-\alpha$ confidence bound for $\sigma_{A}^{2}$ using Bulmer-Morigutti's method is $L_{B M}$ and $U_{B M}$ where

$$
\begin{array}{ll}
L_{B M}=(1 / b)\left\{S_{E}^{2}\left[F_{1-\alpha: n_{1}, \infty}^{-1} F-1-F_{1-\alpha: n_{1}, n_{2}} F^{-1}\left(F_{1-\alpha: n_{1}, n_{2}} F_{1-\alpha: n_{1}, \infty}^{-1}-1\right)\right]\right\} & \text { if } F \geq F_{1-\alpha: n_{1}, n_{2}} \\
L_{B M}=0 & \text { if } F<F_{1-\alpha: n_{1}, n_{2}} \\
& \\
U_{B M}=(1 / b)\left\{S_{E}^{2}\left[F_{\alpha: n_{1}, \infty}^{-1} F-1-F_{\alpha: n_{1}, n_{2}} F^{-1}\left(F_{\alpha: n_{1}, n_{2}} F_{\alpha: n_{1}, \infty}^{-1}-1\right)\right]\right\} & \text { if } F \geq F_{\alpha: n_{1}, n_{2}} \\
U_{B M}=0 & \text { if } F<F_{\alpha: n_{1}, n_{2}}
\end{array}
$$

where $F=S_{A}^{2} / S_{E}^{2}$.

For the Bulmer-Moriguti procedure it is not known if $P\left[L_{B M} \leq \sigma_{A}^{2} \leq U_{B M}\right]$ is $\geq 1-\alpha$

\section{Two Other Methods}

Methods 4 and 5 for obtaining confidence intervals, for $\sigma_{A}^{2}$ will be based on the $1-\alpha$ confidence intervals for $\sigma_{A}^{2}+\sigma_{E}^{2} / b, \quad \sigma_{A}^{2} / \sigma_{E}^{2}$ and $\sigma_{E}^{2}$ respectively given below in (8), (9), (10). See Graybill (1976).

$$
L_{1} \leq \sigma_{A}^{2}+\sigma_{E}^{2} / b \leq U_{1}
$$

where

$$
\begin{gathered}
L_{1}=S_{A}^{2} / b F_{1-\alpha / 2: n_{1}, \infty} \\
U_{1}=S_{A}^{2} / b F_{\alpha / 2: n_{1}, \infty} \\
L_{2} \leq \sigma_{A}^{2} / \sigma_{E}^{2} \leq U_{2}
\end{gathered}
$$

where

$$
\begin{aligned}
& L_{2}=\left[\left(S_{A}^{2} / S_{E}^{2} F_{1-\alpha / 2: n_{1}, n_{2}}\right)-1\right] / b \\
& U_{2}=\left[\left(S_{A}^{2} / S_{E}^{2} F_{\alpha / 2: n_{1}, n_{2}}\right)-1\right] / b .
\end{aligned}
$$




$$
L_{3} \leq \sigma_{E}^{2} \leq U_{3}
$$

where

$$
\begin{aligned}
& L_{3}=S_{E}^{2} / F_{1-\alpha / 2: n_{2}, \infty} \\
& U_{3}=S_{E}^{2} / F_{\alpha / 2: n_{2}, \infty} .
\end{aligned}
$$

Method 4:

By the Bonferroni method the intersection of (8) and (10) gives the upper and lower confidence bounds $L_{4}$ and $U_{4}$ respectively for $\sigma_{A}^{2}$ with confidence coefficient $\geq 1-2 \alpha$, where $L_{4}$ and $U_{4}$ are given by

$L_{4}=L_{1}-\left(U_{3} / b\right)$ and $U_{4}=U_{1}-\left(L_{3} / b\right)$.

Hence substituting for $U_{1}, U_{3}, L_{1}, L_{3}$ we get

$$
P\left[L_{4} \leq \sigma_{A}^{2} \leq U_{4}\right] \geq 1-2 \alpha
$$

where

$$
L_{4}=S_{A}^{2} / b F_{1-\alpha: n_{1}, \infty}-S_{E}^{2} / b F_{\alpha: n_{2}, \infty}
$$

and

$$
U_{4}=S_{A}^{2} / b F_{\alpha: n_{1}, \infty}-S_{E}^{2} / b F_{1-\alpha: n_{2}, \infty}
$$

For this method $P\left[L_{4} \leq \sigma_{A}^{2} \leq U_{4}\right]$ is not always $\geq 1-\alpha$

\section{Method 5:}

By the Bonferroni method the intersection of (9) and (10) gives an upper and lower confidence limits $L_{5}$ and $U_{5}$ respectively for $\sigma_{A}^{2}$ with confidence coefficient $\geq 1-2 \alpha$, where $L_{5}$ and $U_{5}$ are given by

$$
L_{5}=\left(L_{2}\right)\left(L_{3}\right) \text { and } U_{5}=\left(U_{2}\right)\left(U_{3}\right) \text {. }
$$

Substituting for $U_{2}, U_{3}, L_{2}, L_{3}$ we get

$$
P\left[L_{5} \leq \sigma_{A}^{2} \leq U_{5}\right] \geq 1-2 \alpha
$$


where

$$
\begin{aligned}
& L_{5}=S_{A}^{2} /\left(b F_{1-\alpha: n_{1}, \infty} F_{1-\alpha: n_{1}, n_{2}}\right)-S_{E}^{2} /\left(b F_{1-\alpha: n_{2}, \infty}\right) \\
& U_{5}=S_{A}^{2} /\left(b F_{\alpha: n_{1}, \infty} F_{\alpha: n_{1}, n_{2}}\right)-S_{E}^{2} /\left(b F_{\alpha: n_{2}, \infty}\right) .
\end{aligned}
$$

For this method $P\left[L_{5} \leq \sigma_{A}^{2} \leq U_{5}\right]$ is not always $\geq 1-\alpha$.

\section{Unbalanced One-Way Design}

The above five methods are appropriate for balanced one-way models. Now consider the unbalanced model given by

$$
Y_{i j}=\mu+A_{i}+E_{i j} \quad i=1, \ldots, a \quad j=1, \ldots, b_{i}
$$

where $\mu$ is a constant parameter, $A_{i}$ and $E_{i j}$ are independent normal random variables with zero means and variances $\sigma_{A}^{2}$ and $\sigma_{E}^{2}$ respectively.

In this section we will present three new methods for obtaining confidence intervals for $\sigma_{A}^{2}$ for the model in (15). The three methods are

Method A: A modification of TW procedure.

Method B:A modification of method 4.

Method C: A modification of method 5.

Any of the five methods presented in section 2 can be modified for the unbalanced case but we chose TW's method rather than Howe's or Bulmer-Moriguti's method to modify because it has been shown that of the three methods, although Howe's method is the best, TW's method is "almost" as good as Howe's method and in many cases is "as" good. Also it has been proved by Wang (1990) that the confidence coefficient using the TW method is $\geq 1-\alpha$. In addition the TW formula is the simplest of the three methods to compute. We also examine methods $\mathrm{B}$ and $\mathrm{C}$ for the unbalanced case since they have not been previously examined.

First we state three theorms that will be used to derive methods $\mathrm{A}, \mathrm{B}$, and C.

\section{Theorem 1}

In the unbalanced model $Y_{i j}=\mu+A_{i}+E_{i j}$ let $\mathbf{Y}=\left[\bar{Y}_{1}, \bar{Y}_{2}, \ldots, \bar{Y}_{a}\right]^{T}$ where $\bar{Y}_{i}=\left(1 / b_{i}\right) \sum_{j=1}^{b_{i}} Y_{i j}$. Then $\mathbf{Y} \sim M V N(\mu \mathbf{1}, \boldsymbol{\Sigma})$ where $\boldsymbol{\Sigma}=\sigma_{A}^{2} \mathbf{I}+\sigma_{E}^{2} \mathbf{K}$ and where $\mathbf{K}$ is a diagonal matrix with $1 / b_{i}$ on the ith diagonal.

\section{Theorem 2}

In the unbalanced model let $\mathbf{Y}^{\prime} \mathbf{A Y}=\mathbf{Y}^{\prime}[\mathbf{I}-(1 / a) \mathbf{J}] \mathbf{Y}=\sum_{i=1}^{a}\left(\bar{Y}_{i}-\bar{Y}\right)^{2}$ where $\bar{Y}=(1 / a) \sum_{i=1}^{a} \bar{Y}_{i}$; then $\mathbf{Y}^{\prime} \mathbf{A Y}$ is distributed as $\sum_{i=1}^{a-1} \gamma_{i} V_{i}$ where $\gamma_{i}$ are the 
non-zero characteristic roots of $\mathbf{A} \boldsymbol{\Sigma}$ and $V_{i}$ are independent chi-squared random variables where each has one degree of freedom. For a discussion of this theorem see Graybill (1976).

\section{Theorem 3}

If $\gamma_{\min }$ and $\gamma_{\max }$ are the minimum and maximum non-zero characteristic roots of $\mathbf{A} \boldsymbol{\Sigma}$, then

$$
\theta_{\min } \leq \gamma_{\min } \leq \gamma_{\max } \leq \theta_{\max },
$$

where $\theta_{\min }$ and $\theta_{\max }$ are the minimum and maximum characteristic roots of $\boldsymbol{\Sigma}$. We will outline a proof of this theorem.

$\mathbf{A} \boldsymbol{\Sigma}=\sigma_{A}^{2} \mathbf{A}+\sigma_{E}^{2} \mathbf{A} \mathbf{K}$ where $\mathbf{A}=\mathbf{I}-(1 / a) \mathbf{J}$ is an idempotent matrix of rank $a-1$. Thus there exists an orthogonal matrix $\mathbf{Q}$ such that

$$
\mathbf{Q}^{\prime} \mathbf{A Q}=\left[\begin{array}{cc}
0 & \mathbf{0} \\
\mathbf{0} & \mathbf{I}_{a-1}
\end{array}\right]
$$

Let $\Upsilon(\mathbf{A} \boldsymbol{\Sigma})$ be the characteristic roots of $\mathbf{A} \boldsymbol{\Sigma}$, then we have the following. $\Upsilon \mathbf{A} \boldsymbol{\Sigma})=\Upsilon(\mathbf{A} \boldsymbol{\Sigma} \mathbf{A})=\Upsilon\left(\mathbf{Q}^{\prime} \mathbf{A} \mathbf{Q} \mathbf{Q}^{\prime} \mathbf{\Sigma} \mathbf{Q} \mathbf{Q}^{\prime} \mathbf{A} \mathbf{Q}\right)=\Upsilon(\mathbf{G})$ where $\mathbf{G}$ is given by

$$
G=\left[\begin{array}{cc}
0 & 0 \\
0 & \Sigma_{2}
\end{array}\right]
$$

where $\boldsymbol{\Sigma}_{\mathbf{2}}$ is a principal $(a-1) \times(a-1)$ submatrix of $\mathbf{Q}^{\prime} \mathbf{\Sigma} \mathbf{Q}$.

By the seperation theorem (Wilkinson 1972) if $\theta_{1} \leq \theta_{2} \leq \ldots \leq \theta_{a}$ are the characteristic roots of $\boldsymbol{\Sigma}$ and $\gamma_{2} \leq \ldots \leq \gamma_{a}$ are the characteristic roots of $\boldsymbol{\Sigma}_{2}$ then

$$
\theta_{1} \leq \gamma_{2} \leq \theta_{2} \ldots \leq \gamma_{a} \leq \theta_{a}
$$

Since the non-zero characteristic roots of $\mathbf{A} \Sigma$ are the same as the characteristic roots of $\Sigma_{2}$ it follows that

$$
\theta_{\min } \leq \gamma_{\min } \leq \gamma_{\max } \leq \theta_{\max }
$$

This completes the proof.

Let $r_{1}=a-1$ and we have

$1-\alpha=P\left[\sum_{i=1}^{r_{1}} V_{i} \leq r_{1} F_{1-\alpha: r_{1} \infty}\right]=P\left[\sum_{i=1}^{r_{1}} \gamma_{\max } V_{i} \leq \gamma_{\max } r_{1} F_{1-\alpha: r_{1}, \infty}\right]$.

But $\sum \gamma_{i} V_{i} \leq \sum \gamma_{\max } V_{i} \leq \sum \theta_{\max } V_{i}$ so we get $P\left[\sum_{i=1}^{r_{1}} \gamma_{i} V_{i} \leq \theta_{\max } r_{1} F_{1-\alpha, r_{1}, \infty}\right] \geq$ $1-\alpha$.

Substituting $\mathbf{Y}^{\prime} \mathbf{A Y}$ for $\sum \gamma_{i} V_{i}$ we get

$$
P\left(\mathbf{Y}^{\prime} \mathbf{A Y} / \theta_{\max } \leq r_{1} F_{1-\alpha, r_{1}, \infty}\right) \geq 1-\alpha
$$


Similarly

$1-\alpha=P\left[\sum_{i=1}^{r_{1}} V_{i} \geq r_{1} F_{1-\alpha: r_{1}, \infty}\right]=P\left[\sum_{i=1}^{r_{1}} \gamma_{\min } V_{i} \geq \gamma_{\min } r_{1} F_{1-\alpha: r_{1}, \infty}\right]$.

But $\sum \gamma_{i} V_{i} \geq \sum \gamma_{\min } V_{i} \geq \sum \theta_{\min } V_{i}$, so we get $P\left[\sum_{i=1}^{r_{1}} \gamma_{i} V_{i} \geq \theta_{\min } r_{1} F_{1-\alpha, r_{1}, \infty}\right] \geq$ $1-\alpha$.

Substituting $\mathbf{Y}^{\prime} \mathbf{A Y}$ for $\sum \gamma_{i} V_{i}$ we get

$$
P\left(\mathbf{Y}^{\prime} \mathbf{A Y} / \theta_{\min } \geq r_{1} F_{1-\alpha, r_{1}, \infty}\right) \geq 1-\alpha .
$$

But $\boldsymbol{\Sigma}=\sigma_{A}^{2} \mathbf{I}+\sigma_{E}^{2} \mathbf{K}$ where $\mathbf{K}=\operatorname{diag}\left(1 / b_{1}, 1 / b_{2}, \ldots, 1 / b_{a}\right)$. Hence the charcteristic roots of $\Sigma$ are

$$
\sigma_{A}^{2}+\sigma_{E}^{2} / b_{i} \quad \text { for } i=1, \ldots, a
$$

Thus

$$
\theta_{\min }=\sigma_{A}^{2}+\sigma_{E}^{2} / M
$$

and

$$
\theta_{\max }=\sigma_{A}^{2}+\sigma_{E}^{2} / m
$$

where $\mathrm{m}$ and $\mathrm{M}$ are the minimum and maximum of $b_{i} s$ respectively for $i=1, \ldots, a$. Hence

$$
P\left(\mathbf{Y}^{\prime} \mathbf{A Y} / r_{1} F_{1-\alpha, r_{1}, \infty} \leq \sigma_{A}^{2}+\sigma_{E}^{2} / m\right) \geq 1-\alpha
$$

and

$$
P\left(\mathbf{Y}^{\prime} \mathbf{A Y} / r_{1} F_{\alpha, r_{1}, \infty} \geq \sigma_{A}^{2}+\sigma_{E}^{2} / M\right) \geq 1-\alpha .
$$

We use (22) and (23) to derive the three methods $\mathrm{A}, \mathrm{B}$ and $\mathrm{C}$ for obtaining confidence intervals for $\sigma_{A}^{2}$.

Method A - Modification of TW procedure

Replacing $S_{A}^{2}$ with $\mathbf{Y}^{\prime} \mathbf{A Y}$ in equations (2), (3) and using the minimum of $E\left(\mathbf{Y}^{\prime} \mathbf{A Y}\right)$ instead of $E\left(S_{A}^{2}\right)$ we get a modified version of the lower bound of the TW formula. Using the maximum of $E\left(\mathbf{Y}^{\prime} \mathbf{A Y}\right)$ instead of $E\left(S_{A}^{2}\right)$ we get a modified form of the upper bound of the TW formula. The lower and upper bounds are given by $L_{A}$ and $U_{A}$ where

$$
L_{A}=\left[\mathbf{Y}^{\prime} \mathbf{A Y} / r_{1}-\left(F_{1-\alpha: r_{1}, r_{2}} S_{E}^{2}\right) / M\right] / F_{1-\alpha: r_{1}, \infty}
$$

and

$$
U_{A}=\left[\mathbf{Y}^{\prime} \mathbf{A Y} / r_{1}-\left(F_{\alpha: r_{1}, r_{2}} S_{E}^{2}\right) / m\right] / F_{\alpha: r_{1}, \infty}
$$


where $S_{E}^{2}=\sum_{i=1}^{a} \sum_{j=1}^{b_{j}}\left(Y_{i j}-\bar{Y}_{i}\right)^{2} / r_{2}, r_{1}=a-1, r_{2}=b .-a, b .=\sum_{i} b_{i}$ and $\mathbf{Y}^{\prime} \mathbf{A Y}=\sum_{i}\left(\bar{Y}_{i}-\bar{Y}\right)^{2}$.

Method B - Modification of Method 4

In order to modify method 4 we will take the intersection of (22) and (23) with equation (10), the points of intersection will give us the lower and upper bounds for $\sigma_{A}^{2}$ as $L_{B}$ and $U_{B}$ respectively where.

$$
\begin{aligned}
& L_{B}=\mathbf{Y}^{\prime} \mathbf{A Y} / r_{1} F_{1-\alpha: r_{1}, \infty}-S_{E}^{2} / M F_{\alpha: r_{2}, \infty} \\
& U_{B}=\mathbf{Y}^{\prime} \mathbf{A Y} / r_{1} F_{\alpha: r_{1}, \infty}-S_{E}^{2} / m F_{1-\alpha: r_{2}, \infty}
\end{aligned}
$$

where $r_{2}=b .-a$.

\section{Method C - Modification of Method 5}

In the unbalanced one-way model Wald (1940) gave a procedure for finding exact lower and upper confidence bounds for $\tau=\sigma_{A}^{2} / \sigma_{E}^{2}$. This method requires the solution of two nonlinear equations. The $1-\alpha$ lower and upper confidence bounds given by Wald are denoted by $L_{W}$ and $U_{W}$ respectively where

$$
P\left[L_{W} \leq \tau \leq U_{W}\right]=1-\alpha
$$

where $L_{W}$ is the root of the equation

$$
f(\tau)=F_{\alpha: r_{1}, r_{2}}
$$

and $U_{W}$ is the root of the equation

$$
f(\tau)=F_{1-\alpha: r_{1}, r_{2}}
$$

where

$$
f(\tau)=\sum_{i=1}^{a} w_{i}\left(\bar{Y}_{i}-\sum_{i} w_{i} \bar{Y}_{i} / \sum_{i} w_{i}\right)^{2} /(a-1) S_{E}^{2}
$$

and where $w_{i}=b_{i} /\left(1+b_{i} \tau\right)$.

By the Bonferroni method the intersection of (28) with equation (10) gives the lower and upper bounds for $\sigma_{A}^{2}$ as $L_{C}$ and $U_{C}$ where

$$
\begin{aligned}
& L_{C}=\left(L_{W}\right)\left(L_{3}\right) \\
& U_{C}=\left(U_{W}\right)\left(U_{3}\right)
\end{aligned}
$$




\section{Evaluation of the Procedures}

The only known method for obtaining confidence intervals with confidence coefficients $\geq 1-\alpha$ for the unbalanced model in (15) is to discard data at random in each cell so that all cells contain $\mathrm{m}=\min \left(b_{i}\right)$ observations and use the TW method for the resulting balanced model. We will denote this method as the discarded TW method, DTW.

Simulation was used to evaluate methods A, B, and C, by computing confidence coefficients and expected widths. These were compared with the DTW procedure as the standard. It can be shown that the confidence coefficients for methods A, B, C and DTW depend on the unknown parameters $\sigma_{A}^{2}$ and $\sigma_{E}^{2}$ only through $\rho$ where $\rho=\sigma_{A}^{2} /\left(\sigma_{A}^{2}+\sigma_{E}^{2}\right)$. Thus the confidence coefficients depend on $b_{i}$, a, $1-\alpha$, which are known and $\rho$ which is unknown. For details see Fayyad (1993).

Simulations were used to evaluate and compare the methods. The values of $\rho$ were taken to be $0.01(0.01) 0.1,0.1(0.1) 0.9,0.99$. The values of a used were $3,4,8$ and 10 ; various values of $b_{i}$ were used for each value of $a ; 1-\alpha$ was taken as $0.90,0.95,0.99$. Tables (1), (2), (3) and (4) show results for $1-\alpha=0.95$. For details of simulation and results for $1-\alpha=0.90$ and $1-\alpha=0.99$ you can consult Fayyad (1993).

The 'cxpected widths' $E\left|L-\sigma_{A}^{2}\right| /\left(\sigma_{A}^{2}+\sigma_{E}^{2}\right)$ were used for the lower bounds, and $E\left|U-\sigma_{A}^{2}\right| /\left(\sigma_{A}^{2}+\sigma_{E}^{2}\right)$ for the upper bounds. The average widths were computed for methods $\mathrm{A}, \mathrm{B}, \mathrm{C}$ and DTW. The ratio of the average width for methods $\mathrm{A}, \mathrm{B}$, and $\mathrm{C}$ to the average width using the DTW procedure was computed. Thus to evaluate procedures $\mathrm{A}, \mathrm{B}$ and $\mathrm{C}$ for lower bounds we computed

$$
\begin{gathered}
E\left|L_{A}-\sigma_{A}^{2}\right| / E\left|L_{D T W}-\sigma_{A}^{2}\right|, \\
E\left|L_{B}-\sigma_{A}^{2}\right| / E\left|L_{D T W}-\sigma_{A}^{2}\right|
\end{gathered}
$$

and

$$
E\left|L_{C}-\sigma_{A}^{2}\right| / E\left|L_{D T W}-\sigma_{A}^{2}\right|
$$

The same was done for upper bounds.

Tables (1), (2), (3) and (4) summarize the results obtained. Tables (1) and (2) show the ranges of confidence coefficients where the confidence coefficients are calculated for each value of $\rho$ and the minimum and maximum confidence coefficients are given. Tables (3) and (4) give the minimum and maximum values of ratios of expected widths where the ratios are calculated for each value of $\rho$. From Tables (1) and (2) the confidence coefficients for upper and lower confidence bounds are $\geq 1-\alpha$ except for one case where method $\mathrm{C}$ does not attain the stated confidence coefficient for the upper bound. From Table (3) for moderately unbalanced data method A gives the lowest expected width.

Once the data becomes very unbalanced, method A gives larger expected 
widths than the DTW method; however method C has lower expected widths than method $\mathrm{A}$ in some of the cases but it still has slightly larger expected width than the DTW procedure. These unbalanced cases are extreme and would very rarely occur in practical situations; hence for practical situations method A seems to be the 'best' for upper bounds. For the lower bounds (Table 4) method A has the smallest expected widths for balanced, moderately unbalanced and very unbalanced designs, hence method A seems to be the best of the four procedures for lower bounds. So overall we recommend that method A be used to compute upper, lower and two sided confidence intervals for $\sigma_{A}^{2}$ in the unbalanced one-way variance components model.

\section{An Example}

Swallow and Searle (1978) presented the data shown in the Table below in which five groups of vegetable oil were randomly selected from a moving production line and weighted. We will compute lower, and upper confidence bounds for $\sigma_{A}^{2}$, the variance of a single weighing, using method $\mathrm{A}$ and method $\mathrm{B}$. The data are used to calculate $\mathbf{Y}^{\prime} \mathbf{A Y}=0.01425$ and $S_{E}^{2}=0.00214$, and these were substituted into formulas (24), (25), (26) and (27). The values of $L_{A}, L_{B}, U_{A}$ and $U_{B}$ respectively were obtained for $1-\alpha=0.95$. The values are: $L_{A}=0.00089, U_{A}=0.019$, $L_{B}=0.00047$ and $U_{B}=0.019$.

Weights of Bottles (in ounces)

\begin{tabular}{|c|c|c|c|c|c|}
\hline & & & Group & & \\
\hline & 1 & 2 & 3 & 4 & 5 \\
\hline & 15.70 & 15.69 & 15.75 & 15.68 & 15.65 \\
\hline & 15.68 & 15.72 & 15.82 & 15.66 & 15.60 \\
\hline & 15.64 & & 15.75 & 15.59 & \\
\hline & 15.60 & & 15.71 & & \\
\hline & & & 15.84 & & \\
\hline $\bar{Y}_{i}$ & 15.655 & 15.7 & 15.774 & 15.643 & 15.625 \\
\hline
\end{tabular}


Table 1

Ranges Of Confidence Coefficients For Upper Bounds as $\rho$ varies from 0 to 1.

$$
1-\alpha=0.95
$$

\begin{tabular}{|c|c|c|c|c|c|}
\hline $\mathrm{a}$ & $b_{i}$ & $\begin{array}{l}\text { Range for } \\
\text { Method C }\end{array}$ & $\begin{array}{l}\text { Range for } \\
\text { Method B }\end{array}$ & $\begin{array}{l}\text { Range for } \\
\text { DTW }\end{array}$ & $\begin{array}{l}\text { Range for } \\
\text { Method A }\end{array}$ \\
\hline 3 & 234 & $0.951-0.985$ & $0.951-0.982$ & $0.949-0.952$ & $0.950-0.955$ \\
\hline 3 & 21020 & $0.952-0.970$ & $0.951-0.988$ & $0.951-0.953$ & $0.951-0.961$ \\
\hline 3 & 221000 & $0.948-0.955$ & $0.951-0.999$ & $0.951-0.951$ & $0.950-0.971$ \\
\hline 3 & 101010 & $0.953-0.971$ & $0.951-0.966$ & $0.951-0.953$ & $0.951-0.952$ \\
\hline 3 & 102030 & $0.952-0.965$ & $0.951-0.973$ & $0.951-0.952$ & $0.951-0.956$ \\
\hline 4 & 2222 & $0.952-0.996$ & 0.954-0.983 & $0.951-0.953$ & $0.951-0.955$ \\
\hline 4 & 2223 & $0.952-0.994$ & 0.953-0.987 & $0.951-0.953$ & $0.952-0.957$ \\
\hline 4 & 2244 & 0.951-0.990 & 0.954-0.988 & $0.952-0.954$ & $0.951-0.958$ \\
\hline 4 & 22100100 & $0.952-0.962$ & 0.954-0.998 & $0.953-0.953$ & $0.954-0.976$ \\
\hline 4 & 10101011 & $0.956-0.973$ & $0.953-0.971$ & $0.952-0.953$ & $0.953-0.954$ \\
\hline 4 & 101010100 & $0.952-0.964$ & 0.953-0.994 & $0.953-0.953$ & $0.953-0.971$ \\
\hline \multirow[t]{2}{*}{8} & 2345 & & & & \\
\hline & 6789 & $0.950-0.983$ & $0.954-0.994$ & $0.946-0.957$ & $0.954-0.964$ \\
\hline \multirow[t]{2}{*}{8} & 2222 & & & & \\
\hline & 2221000 & $0.938-0.960$ & $0.954-1.000$ & $0.953-0.954$ & $0.946-0.988$ \\
\hline \multirow[t]{2}{*}{8} & 10101010 & & & & \\
\hline & 10101010 & $0.956-0.975$ & 0.954-0.973 & $0.952-0.954$ & $0.954-0.956$ \\
\hline \multirow[t]{2}{*}{8} & 10203040 & & & & \\
\hline & 50607080 & $0.955-0.963$ & $0.954-0.987$ & $0.949-0.954$ & $0.954-0.968$ \\
\hline \multirow[t]{2}{*}{8} & 50505050 & & & & \\
\hline & 505050100 & $0.957-0.963$ & $0.954-0.980$ & $0.953-0.954$ & $0.954-0.966$ \\
\hline \multirow[t]{2}{*}{8} & 50505050 & & & & \\
\hline & 5050100100 & $0.957-0.963$ & $0.954-0.973$ & $0.952-0.954$ & $0.954-0.960$ \\
\hline \multirow[t]{2}{*}{10} & 23456 & & & & \\
\hline & 7891011 & 0.954-0.979 & $0.945-0.997$ & $0.944-0.948$ & $0.945-0.969$ \\
\hline \multirow[t]{2}{*}{10} & 22222 & & & & \\
\hline & 22221000 & 0.944-0.958 & $0.945-1.00$ & $0.945-0.947$ & $0.945-0.993$ \\
\hline \multirow[t]{2}{*}{10} & 1010101010 & & & & \\
\hline & 1010101010 & $0.951-0.977$ & $0.945-0.967$ & $0.945-0.950$ & $0.945-0.950$ \\
\hline \multirow[t]{2}{*}{10} & 1020304050 & & & & \\
\hline & 60708090100 & $0.954-0.960$ & $0.945-0.995$ & $0.944-0.946$ & $0.945-0.974$ \\
\hline \multirow[t]{2}{*}{10} & 2020202020 & & & & \\
\hline & 202020201000 & $0.947-0.957$ & $0.945-1.00$ & $0.945-0.946$ & 0.945-0.991 \\
\hline \multirow[t]{2}{*}{10} & 5050505050 & & & & \\
\hline & 5050505060 & 0.952 & 967 & 945 & $0.945-0.952$ \\
\hline 10 & $\begin{array}{lllll}50 & 50 & 50 & 50 & 50 \\
50 & 50 & 50 & 50 & 100\end{array}$ & $0.953-0.960$ & $0.945-0.982$ & $0.945-0.947$ & $0.945-0.963$ \\
\hline
\end{tabular}


Table 2

Ranges Of Confidence Coefficients For Lower Bounds as $\rho$ varies from 0 to 1. $1-\alpha=0.95$

\begin{tabular}{|c|c|c|c|c|c|}
\hline $\mathrm{a}$ & $b_{i}$ & $\begin{array}{l}\text { Range for } \\
\text { Method C }\end{array}$ & $\begin{array}{l}\text { Range for } \\
\text { Method B }\end{array}$ & $\begin{array}{l}\text { Range for } \\
\text { DTW }\end{array}$ & $\begin{array}{l}\text { Range for } \\
\text { Method A }\end{array}$ \\
\hline 3 & 234 & $0.963-1.000$ & $0.952-0.996$ & $0.951-0.970$ & $0.951-0.973$ \\
\hline 3 & 21020 & 0.960-0.992 & 0.951-0.999 & $0.950-0.953$ & $0.951-0.978$ \\
\hline 3 & 221000 & $0.951-0.961$ & $0.951-0.986$ & $0.950-0.952$ & $0.951-0.966$ \\
\hline 3 & 101010 & 0.959-0.992 & $0.951-0.984$ & $0.951-0.956$ & $0.950-0.955$ \\
\hline 3 & 102030 & $0.960-0.984$ & $0.951-0.997$ & $0.951-0.952$ & $0.951-0.970$ \\
\hline 4 & 2222 & $0.963-1.000$ & $0.951-0.993$ & $0.947-0.971$ & $0.949-0.974$ \\
\hline 4 & 2223 & $0.963-1.000$ & $0.951-0.993$ & $0.947-0.971$ & $0.950-0.971$ \\
\hline 4 & 2244 & $0.961-1.000$ & $0.950-0.996$ & $0.949-0.965$ & $0.949-0.973$ \\
\hline 4 & 22100100 & 0.953-0.971 & 0.949-0.995 & $0.948-0.950$ & $0.949-0.976$ \\
\hline 4 & 10101011 & $0.956-0.992$ & $0.948-0.984$ & $0.947-0.952$ & $0.947-0.951$ \\
\hline 4 & 101010100 & $0.954-0.977$ & $0.948-0.987$ & $0.947-0.949$ & $0.948-0.959$ \\
\hline \multirow[t]{2}{*}{8} & 2345 & & & & \\
\hline & 6789 & $0.957-0.998$ & $0.952-1.000$ & $0.949-0.956$ & $0.951-0.987$ \\
\hline \multirow[t]{2}{*}{8} & 2222 & & & & \\
\hline & 2221000 & $0.951-0.966$ & $0.950-0.978$ & $0.948-0.950$ & $0.950-0.959$ \\
\hline \multirow[t]{2}{*}{8} & 10101010 & & & & \\
\hline & 10101010 & 0.961-0.992 & $0.950-0.984$ & $0.950-0.953$ & $0.950-0.954$ \\
\hline \multirow[t]{2}{*}{8} & 50505050 & & & & \\
\hline & 505050100 & $0.960-0.975$ & $0.950-0.973$ & $0.949-0.950$ & $0.950-0.956$ \\
\hline \multirow[t]{2}{*}{8} & 50505050 & & & & \\
\hline & 100100100100 & $0.961-0.971$ & $0.950-0.985$ & $0.949-0.950$ & $0.950-0.965$ \\
\hline \multirow[t]{2}{*}{8} & 10203040 & & & & \\
\hline & 50607080 & $0.959-0.976$ & $0.950-1.000$ & 0.949-0.950 & 0.950-0.992 \\
\hline \multirow[t]{2}{*}{10} & 23456 & & & & \\
\hline & 7891011 & $0.955-0.996$ & $0.951-1.000$ & $0.946-0.955$ & $0.950-0.991$ \\
\hline \multirow[t]{2}{*}{10} & 22222 & & & & \\
\hline & 22221000 & $0.950-0.968$ & $0.950-0.979$ & $0.949-0.950$ & $0.950-0.957$ \\
\hline \multirow[t]{2}{*}{10} & 1010101010 & & & & \\
\hline & 1010101010 & $0.958-0.992$ & $0.950-0.982$ & $0.950-0.953$ & $0.950-0.953$ \\
\hline \multirow[t]{2}{*}{10} & 1020304050 & & & & \\
\hline & 60708090100 & $0.959-0.973$ & $0.950-1.000$ & $0.948-0.951$ & $0.950-0.994$ \\
\hline \multirow[t]{2}{*}{10} & 2020202020 & & & & \\
\hline & 202020201000 & $0.953-0.966$ & $0.949-0.976$ & $0.949-0.951$ & $0.951-0.956$ \\
\hline \multirow[t]{2}{*}{10} & 5050505050 & & & & \\
\hline & 5050505060 & $0.959-0.974$ & $0.950-0.967$ & $0.950-0.951$ & $0.950-0.952$ \\
\hline 10 & 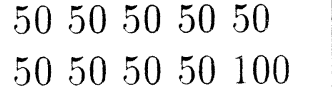 & $0.960-0.973$ & $0.950-0.972$ & $0.950-0.951$ & $0.950-0.955$ \\
\hline
\end{tabular}


$\underline{\text { Table } 3}$

Ranges Of Ratios Of Average Widths Of Each Of The Three Methods To The Expected Width Using DTW Method For Upper Bounds for $1-\alpha=0.95$

\begin{tabular}{|c|c|c|c|c|}
\hline $\mathrm{a}$ & $b_{i}$ & $\begin{array}{l}\text { Range for Ratio } \\
\text { Method C to DTW }\end{array}$ & $\begin{array}{l}\text { Range for Ratio } \\
\text { Method B to DTW }\end{array}$ & $\begin{array}{l}\text { Range for Ratio } \\
\text { Method A to DTW }\end{array}$ \\
\hline 3 & 234 & $2.652-3.766$ & $0.754-0.999$ & $0.739-0.999$ \\
\hline 3 & 21020 & $0.730-1.662$ & $0.469-0.997$ & $0.466-0.997$ \\
\hline 3 & 221000 & $0.728-1.080$ & 0.713-0.999 & $0.713-0.999$ \\
\hline 3 & 101010 & $1.670-1.702$ & $1.000-1.015$ & $0.999-1.000$ \\
\hline 3 & 102030 & $0.911-1.420$ & $0.667-1.000$ & $0.662-1.000$ \\
\hline 4 & 2222 & $6.003-6.642$ & $1.000-1.058$ & $0.996-1.000$ \\
\hline 4 & 2223 & $4.212-5.061$ & $0.981-1.000$ & $0.934-1.000$ \\
\hline 4 & 2244 & $2.276-3.284$ & 0.808-0.999 & $0.775-0.999$ \\
\hline 4 & 22100100 & $0.590-1.210$ & $0.580-0.998$ & $0.577-0.998$ \\
\hline 4 & 10101011 & $1.520-1.617$ & $1.000-1.014$ & $0.983-1.000$ \\
\hline 4 & 101010100 & $0.981-1.280$ & $0.870-1.000$ & $0.863-1.000$ \\
\hline \multirow[t]{2}{*}{8} & 2345 & & & \\
\hline & 6789 & $0.717-1.849$ & $0.578-0.998$ & $0.528-0.964$ \\
\hline \multirow[t]{2}{*}{8} & 2222 & & & \\
\hline & 2221000 & $0.913-1.110$ & $1.001-1.244$ & $1.001-1.228$ \\
\hline \multirow[t]{2}{*}{8} & 10101010 & & & \\
\hline & 10101010 & $1.385-1.524$ & $1.000-1.078$ & $0.999-1.000$ \\
\hline \multirow[t]{2}{*}{8} & 10203040 & & & \\
\hline & 50607080 & $0.432-1.198$ & 0.482-0.999 & 0.462-0.999 \\
\hline \multirow[t]{2}{*}{8} & 50505050 & & & \\
\hline & 505050100 & $1.092-1.174$ & $1.000-1.092$ & $1.000-1.061$ \\
\hline \multirow[t]{2}{*}{8} & 50505050 & & & \\
\hline & 100100100100 & $0.927-1.148$ & $0.910-1.000$ & $0.888-1.000$ \\
\hline \multirow[t]{2}{*}{10} & 23456 & & & \\
\hline & 7891011 & $0.564-1.693$ & $0.575-0.998$ & $0.508-0.997$ \\
\hline \multirow{2}{*}{10} & 22222 & & & \\
\hline & 22221000 & $0.939-1.119$ & $1.002-1.400$ & $1.002-1.379$ \\
\hline 10 & $\begin{array}{llllll}10 & 10 & 10 & 10 & 10 \\
10 & 10 & 10 & 10 & 10\end{array}$ & & & \\
\hline \multirow[t]{2}{*}{10} & $\begin{array}{llllll}10 & 10 & 10 & 10 & 10 \\
10 & 20 & 30 & 40 & 50\end{array}$ & $1.344-1.500$ & $1.000-1.092$ & $1.000-1.003$ \\
\hline & 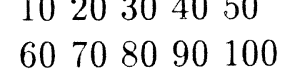 & $0.369-1.169$ & $0401-0909$ & 0000 \\
\hline \multirow[t]{2}{*}{10} & 2020202020 & $0.509-1.109$ & $0.451-0.853$ & \\
\hline & 202020201000 & $0.967-1.111$ & $1.000-1.324$ & $1.000-1.312$ \\
\hline \multirow[t]{2}{*}{10} & 5050505050 & & & \\
\hline & 5050505060 & $1.125-1.178$ & $1.000-1.068$ & $1.000-1.028$ \\
\hline \multirow[t]{2}{*}{10} & 5050505050 & & & \\
\hline & $50505050 \quad 100$ & $1.091-1.170$ & $1.000-1.141$ & $1.000-1.100$ \\
\hline
\end{tabular}


Table 4

Ranges Of Ratios Of Average Widths Of Each Of The Three Methods To The Expected Width Using DTW Method For Lower Bounds for $1-\alpha=0.95$

\begin{tabular}{|c|c|c|c|c|}
\hline $\mathrm{a}$ & $b_{i}$ & $\begin{array}{l}\text { Range for Ratio } \\
\text { Method C to DTW }\end{array}$ & $\begin{array}{l}\text { Range for Ratio } \\
\text { Method B to DTW }\end{array}$ & $\begin{array}{l}\text { Range for Ratio } \\
\text { Method A to DTW }\end{array}$ \\
\hline 3 & 234 & $0.616-1.280$ & $0.600-1.066$ & $0.808-0.996$ \\
\hline 3 & 21020 & $0.623-1.135$ & $0.561-1.086$ & $0.637-1.000$ \\
\hline 3 & 221000 & $0.797-1.020$ & $0.673-1.033$ & $0.766-1.000$ \\
\hline 3 & 101010 & $0.932-1.144$ & $0.931-1.058$ & $1.000-1.010$ \\
\hline \multirow[t]{2}{*}{3} & 102030 & $0.899-1.097$ & $0.895-1.065$ & $0.907-1.000$ \\
\hline & 2222 & $0.612-1.433$ & $0.696-1.110$ & $0.996-1.003$ \\
\hline 4 & 2223 & $0.627-1.402$ & $0.651-1.091$ & 0.932-0.999 \\
\hline 4 & 2244 & $0.651-1.342$ & $0.622-1.096$ & 0.819-0.998 \\
\hline 4 & 22100100 & $0.666-1.065$ & $0.615-1.078$ & $0.671-1.002$ \\
\hline 4 & 10101011 & 0.934-1.168 & $0.932-1.068$ & $0.992-1.000$ \\
\hline 4 & 101010100 & $0.928-1.087$ & $0.927-1.059$ & $0.943-1.001$ \\
\hline \multirow[t]{2}{*}{8} & 2345 & & & \\
\hline & 6789 & $0.722-1.319$ & $0.679-1.189$ & $0.718-1.008$ \\
\hline \multirow[t]{2}{*}{8} & 2222 & & & \\
\hline & 2221000 & $0.892-1.055$ & $0.807-1.055$ & $0.899-1.003$ \\
\hline \multirow[t]{2}{*}{8} & 10101010 & 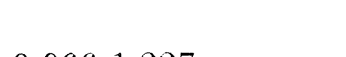 & - & 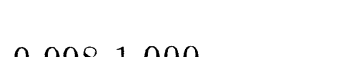 \\
\hline & $\begin{array}{llll}10 & 10 & 10 & 10 \\
50 & 50 & 50 & 50\end{array}$ & $0.966-1.227$ & $0.971-1.092$ & $0.998-1.000$ \\
\hline 8 & 505050100 & $0.990-1.086$ & $1.000-1.055$ & 0.991-1.001 \\
\hline \multirow[t]{2}{*}{8} & 50505050 & & & \\
\hline & 100100100100 & $0.955-1.074$ & $1.000-1.093$ & $0.975-1.007$ \\
\hline \multirow[t]{2}{*}{8} & 10203040 & & $00 c_{1} 11176$ & 0018,1000 \\
\hline & $\begin{array}{l}50607080 \\
23456\end{array}$ & $0.824-1.097$ & $0.961-1.176$ & $0.916-1.020$ \\
\hline \multirow[t]{2}{*}{10} & $\begin{array}{lllll}2 & 3 & 4 & 5 & 6 \\
7 & 8 & 9 & 10 & 11\end{array}$ & & & \\
\hline & 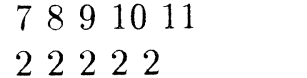 & $0.705-1.304$ & $0.677-1.231$ & $0.687-1.016$ \\
\hline 10 & $\begin{array}{lllll}2 & 2 & 2 & 2 & 2 \\
2 & 2 & 2 & 2 & 1000\end{array}$ & & & \\
\hline \multirow[t]{2}{*}{10} & $\begin{array}{lllllll}2 & 2 & 2 & 2 & 1000 \\
10 & 10 & 10 & 10 & 10\end{array}$ & $0.897-1.065$ & $0.822-1.063$ & 0.907-1.003 \\
\hline & $\begin{array}{lllll}10 & 10 & 10 & 10 & 10 \\
10 & 10 & 10 & 10 & 10\end{array}$ & 0.973-1.239 & $0.977-1.098$ & $0.999-1.003$ \\
\hline \multirow[t]{2}{*}{10} & 1020304050 & & & \\
\hline & 60708090100 & $0.770-1.091$ & $0.968-1.215$ & 0.916-1.034 \\
\hline \multirow[t]{2}{*}{10} & 2020202020 & & & \\
\hline & 202020201000 & $0.953-1.061$ & $1.000-1.061$ & $0.967-1.003$ \\
\hline \multirow[t]{2}{*}{10} & 5050505050 & & & \\
\hline & 5050505060 & $1.000-1.096$ & $1.000-1.054$ & $0.999-1.001$ \\
\hline \multirow[t]{2}{*}{10} & 5050505050 & & & \\
\hline & $\begin{array}{lllll}50 & 50 & 50 & 50 & 100 \\
\end{array}$ & 0.993-1.092 & $1.000-1.061$ & $0.992-1.002$ \\
\hline
\end{tabular}




\section{References}

Bulmer, M. G. (1957). Approximate confidence limits for components of variance. Biometrika 44, 159-167.

Burdick, R. K. and Graybill, F. A. (1984). Confidence intervals on linear combinations of variance components in the unbalanced one-way classification. Technometrics 26, 131-136.

Fayyad, R. S. (1993). Confidence Intervals for Variance Components in Unbalanced Designs. Unpublished Dissertation, Colorado State University, Ft. Collins, Colorado.

Graybill, F. A. (1976). Theory and Application of The Linear Model. Duxbury, North Scituate, Massachusetts.

Howe, W. G. (1974). Approximate confidence limits on the mean of $X+Y$ where $\mathrm{X}$ and $\mathrm{Y}$ are two tabled independent random variables. J. Amer. Stat. Assoc. 69, 789-794

Moriguti, S. (1954). Confidence limits for a variance component. REP. STAT. APPL. RES., JUSE 3, 7-19.

Swallow, W. H. and Searle, S. R. (1978). Minimum variance quadratic unbiased estimation (MIVQUE) of variance components. Technometrics 20, 265-272.

Tukey, J. W. (1951). Components in regression. Biometrics 7, 33-69

Wald, A. (1940). A note on the analysis of variance with unequal class frequencies. Ann. Math. Stat. 11, 96-100.

Wang, C. M. (1990). On ranges of confidence coefficients for confidence intervals on variance components. Comm. Stat.-simula. 19, 1165-1178.

Wilkinson, J. H. (1972) The Algebraic Eigenvalue Problem Clarendon Press, Oxford.

Williams, J. S. (1962). A confidence interval for variance components. Biometrika 49, 278-281. 